\title{
Pharmacokinetics and tissue distribution of SU2162, a novel anticancer drug, after intravenous administration in rats
}

\author{
Zaiyou Tan*, Hui Yang, Ruisi Yan, Ruiling Liu, Xue Li, Qing Ye, Wanshen Guan, Xiaolu Zhang, Yuqing Huang, Chunmei Tong and \\ Wenfei Chen \\ *Correspondence: tanzaiyou@medmail.com.cn

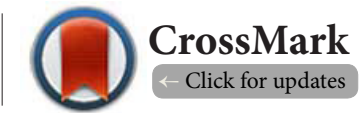 \\ School of Pharmacy, Guangdong Pharmaceutical University, Guangdong, 510006 People's Republic of China.
}

\begin{abstract}
Background: SU2162, a novel anticancer agent, was investigated in the rat, and pharmacokinetics and tissue distribution were observed. These data will be used to design a SU2162 dosage form for clinical use.

Methods: After IV administration of SU2162, HPLC with UV detection was used to analyze rat samples. A two compartment model was used to evaluate the pharmacokinetics of SU2162.

Results: SU2162 pharmacokinetics in the rat depicts a two-compartment model, and the weighting coefficient was $1 / \mathrm{c}^{2}$. The distribution half life $\left(\mathrm{T}_{1 / 2 \mathrm{a}}\right)$ was $0.1066 \mathrm{~h}$; the elimination half life $\left(\mathrm{T}_{1 / 2 \mathrm{kel}}\right)$ was $0.3910 \mathrm{~h}$. SU2162 was distributed widely in tissues studied. The AUC in the spleen was the highest of all the tissues assayed $\left(6.7685 \mathrm{mg} / \mathrm{l}^{\star} \mathrm{h}\right)$. The $\mathrm{LZ}$ in the liver was the greatest $(1.5729$ $1 / \mathrm{h})$ but liver MRT was the smallest $(0.6760 \mathrm{~h})$.

Conclusion: SU2162 is eliminated quickly in the rat and distributes to tissues extensively, and warrants further development as anticancer candidate.
\end{abstract}

Keywords: SU2162, pharmacokinetics, tissue distribution, compartment model, HPLC

\section{Background}

Cancer is a threat to human health and its incidence is increasing worldwide. According to the American Cancer Society (ACS), in 2008, 12.66 million new cancer cases were documented and by 2030 , new cancer cases are estimated to increase by $75 \%$. Not only does cancer causes illness, multiple organ failure and death, it also contributes to social economic losses, and cancer is reported to cause the greatest economic loss than any other disease ( $\$ 895.2$ billion per year), followed by cardiovascular and cerebrovascular diseases, HIV/AIDS, lower respiratory infections (including pneumonia), hepatocirrhosis, and malaria [1].

(3aRS, 4SR, 7RS, 7aSR)-2-(tricyclo-[3.3.1.1 $\left.{ }^{3,7}\right]$ decan-1-yl)4,5,6,7- tetrahydro- 4,7-epoxyisoindoline-1,3-dione(SU2162) is a novel anticancer agent (Figure 1: structure). Pharmacodynamic studies of SU2162 suggest that it has remarkable, dose-response inhibitory effects on glioma growth $\left(\mathrm{IC}_{50}=0.721 \mathrm{mmol} / \mathrm{l}\right)[2]$. The chemical synthesis of SU2162 from norcantharidin and amantadine has been established [2] and its crystal structure is known [3,4]. Also, a methodological study of SU2162 pharmacokinetics has been established [5].

Understanding pharmacokinetics and tissue distribution of SU2162 in the rat will guide future designs of SU2162 dosage forms and direct its clinical use [6]. Here, we report the pharmacokinetics and tissue distribution of SU2162 after administration (iv) in the rat.

\section{Methods}

\section{Reagents and chemicals}

SU2162 was supplied by the School of Pharmacy, Guangdong Pharmaceutical University. Acetonitrile (HPLC grade) was purchased from Tianjin Kermel Chemical Reagent Co, Ltd (Tianjin).

\section{Animals}

Sprague-Dawley rats, weighing $290 \pm 30 \mathrm{~g}$ (pharmacokinetics studies) and $200 \pm 30 \mathrm{~g}$ (tissue distribution studies), were obtained from the Experimental Animal Center of Guangzhou University of Chinese Medicine. They were housed separately in metal cages with access to tap water and standard rat chow ad libitum. Studies were conducted in accordance with the Principles of Laboratory Animal Care (NIH Publication No.85-23, revised 1985). The ethic report number was SD-R-201108005, issued by GDPU Experimental animal center, year 2011.

\section{Administration of SU2162}

Each rat was administered a single dose of SU2162 $(5.5 \mathrm{mg} / \mathrm{kg}$, iv) that had been prepared $(2 \mathrm{mg} / \mathrm{ml})$ in ethanol, propylene glycol and water (1:4:5). The formulation was administered 


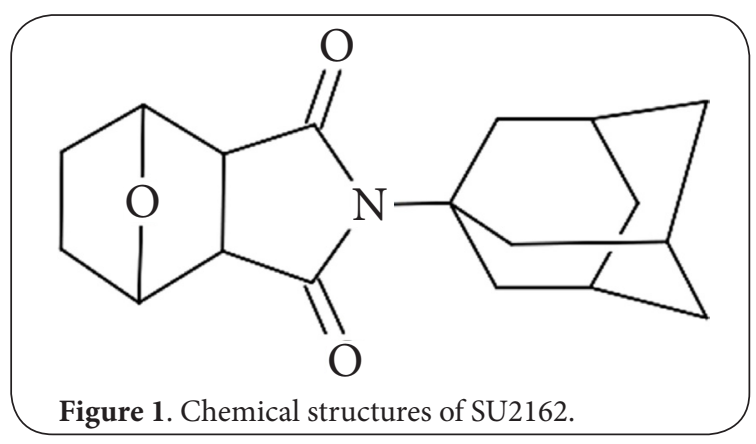

through the tail vein.

\section{Pharmacokinetic study}

Six rats $(290 \pm 30 \mathrm{~g})$, were used for this study ( $\mathrm{N}=3 \mathrm{male} / 3$ female). Blood was ( 0.3 ml) drawn 0.05, 0.1, 0.2, 0.25, 0.33, $0.67,1.33,1.67,2.0$ and $2.5 \mathrm{~h}$ after drug administration from the retro-orbital plexus, and collected in heparinized tubes. Blood samples were centrifuged at 13,000 rpm for $6 \mathrm{~min}$, and the plasma was collected and immediately stored at $-20^{\circ} \mathrm{C}$ and analyzed by HPLC [6].

\section{Tissue distribution study}

Animals were sacrificed $0.03,0.1,0.42,0.83,1.33 \mathrm{~h}$ after drug administration (after blood collection). Then, hearts, livers, spleens, lungs, kidneys, and brains were collected. Three rats $(200 \pm 30 \mathrm{~g})$, were used for each time point. Tissues were cleaned with physiological saline immediately to remove blood, and blotted dry with filter paper. Then, all tissues were frozen at $-20^{\circ} \mathrm{C}$ until analysis.

\section{Sample preparation}

Tissues (1 $\mathrm{g}$ or the entire organ if $1 \mathrm{~g}$ was not achieved) from heart, liver, spleen, lung, kidney, and brain were weighted into $10 \mathrm{ml}$ small beakers. Tissues samples were mixed with double-distilled water (1:1.5), and homogenized for $3 \mathrm{~min}$ using a PT1600E tissuemizer (Kinematica, Swiss).

Then, $375 \mu$ l acetonitrile was added to $125 \mu$ l plasma sample or tissue homogenate for protein precipitation. After vortexing $\sim 5 \mathrm{~min}$, the mixture was centrifuged at $13,000 \mathrm{rpm}$ for 6 $\mathrm{min}$. The supernatant was transferred to clean $0.5 \mathrm{ml}$ centrifuge tubes and dried under a stream of nitrogen. Then the residue was reconstituted with $125 \mu$ lacetonitrile by vortex and ultrasonic mixing for $5 \mathrm{~min}$ and $25 \mu \mathrm{l}$ of this reconstituted solution was injected into the HPLC system for analysis after filtration through a $\varphi 22$-microporous membrane.

\section{HPLC analysis}

An HPLC system with UV detection was used, consisting of a Shimadzu LC-10ATvp pump, a SPD-10Avp detector, and a manual injector with a $20 \mu \mathrm{l}$ fixed loop. A Phenominex prodigy analytical guard column $(12.5 \mathrm{~mm} \times 4.6 \mathrm{~mm})$ was used in tandem with a reversed-phase $\mathrm{C}_{18}$ column (Luna $\mathrm{C}_{18}$ column; $250 \mathrm{~mm} \times 4.6 \mathrm{~mm} ; 5 \mu \mathrm{m}$ particle size; purchased from Phenominex Co. Ltd, Guangzhou, China), and maintained at ambient temperature. Analytes were eluted at $1 \mathrm{ml} / \mathrm{min}$ under isocratic conditions using acetonitrile: water (40:60) for $80 \mathrm{~min}$ and detected at $211 \mathrm{~nm}$. The injection volume was $25 \mu \mathrm{l}$ [7].

Our HPLC plasma method has been previously validated [5]. The SU2162 retention time was $70.133 \mathrm{~min}$. The calibration curve for SU2162 in rat plasma was linear over $0.200-16.00 \mu \mathrm{g} /$ $\mathrm{ml}$ and the detection limit was $0.204 \mu \mathrm{g} / \mathrm{ml}$. The quantification limit was $0.816 \mu \mathrm{g} / \mathrm{ml}$ with a coefficient of variation (CV) of $14.5 \%$ and an accuracy of $92.2 \%$. The precision for each concentration was evaluated by $\mathrm{CV} \%$. The CV\% of the intra-day precision at $0.408,4.08,12.24 \mu \mathrm{g} / \mathrm{ml}$ was $12.36,4.95,8.61 \%$, respectively and the CV\% of the inter-day precision at 0.408 , $4.08,12.24 \mu \mathrm{g} / \mathrm{ml}$ was $6.31,8.63,7.24 \%$, respectively. The CV\% of the relative recovery at $0.408,4.08,12.24 \mu \mathrm{g} / \mathrm{ml}$ was $113.26,114.24,96.45 \%$, respectively. The CV\% of the absolute recovery at $0.408,4.08,12.24 \mu \mathrm{g} / \mathrm{ml}$ was $10.21,4.85,8.54 \%$, respectively. SU2162 for plasma pharmacokinetic studies after freezing at $-20^{\circ} \mathrm{C}$ for 4 days were stable as well.

Extracted plasma samples in reconstituted solutions were stable after five freeze-thaw cycles. The average concentrations of all samples were $95-105 \%$ of the initial concentration (See Tables 1 and 2).

The extracted samples were comprised of blank plasma plus $0.400,4$, or $12 \mu \mathrm{g} / \mathrm{ml}$ of the standard solution and solution samples contained an equivalent concentration of the standard solution without the blank plasma. Absolute recovery of SU2162 was calculated by comparing the respective peak areas of the chromatograms between extracted samples and solution samples (Table 3).

\section{Results}

SU2162 pharmacokinetics was measured in the rat after 5.5 $\mathrm{mg} / \mathrm{kg}$ SU2162 was administered (iv). Statistics were performed

Table 1. Stability of SU2162 in residue after storage at $-20^{\circ} \mathrm{C}$ for 4 days.

\begin{tabular}{|c|c|c|c|}
\hline $\begin{array}{l}\text { Concentration } \\
(\mathrm{mg} / \mathrm{ml})\end{array}$ & $\begin{array}{l}\text { Mean initial } \\
\text { concentration } \\
(\text { mean } \pm S D ; \\
\mathrm{mg} / \mathrm{ml})\end{array}$ & $\begin{array}{l}\text { Mean measured } \\
\text { concentration } \\
(\mathrm{mean} \pm \mathrm{SD} ; \\
\mathrm{mg} / \mathrm{ml})\end{array}$ & $\begin{array}{l}\text { (Mean measured } \\
\text { Concentration/ } \\
\text { Mean initial } \\
\text { Concentration, \%) }\end{array}$ \\
\hline 0.4080 & $0.3857 \pm 0.0579$ & $0.3789 \pm 0.01830$ & $98.25 \%$ \\
\hline 12.24 & $13.28 \pm 1.2860$ & $13.90 \pm 1.2730$ & $104.7 \%$ \\
\hline
\end{tabular}

Table 2. Stability of exacted plasma samples in reconstituted solutions after five freeze-thaw cycles.

\begin{tabular}{llll}
\hline $\begin{array}{l}\text { Concentration } \\
(\mathbf{m g} / \mathbf{m l})\end{array}$ & $\begin{array}{l}\text { Mean initial } \\
\text { concentration } \\
(\mathbf{m e a n} \pm \text { SD; } \\
\mathbf{m g} / \mathbf{m l})\end{array}$ & $\begin{array}{l}\text { Mean measured } \\
\text { concentration } \\
(\mathbf{m e a n} \pm \text { SD; } \\
\mathbf{m g} / \mathbf{m l})\end{array}$ & $\begin{array}{l}\text { (Mean measured } \\
\text { Concentration/ } \\
\text { Mean initial } \\
\text { Concentration, \%) }\end{array}$ \\
\hline 0.4080 & $0.3857 \pm 0.0579$ & $0.4042 \pm 0.06940$ & $104.8 \%$ \\
12.24 & $13.28 \pm 1.2860$ & $13.48 \pm 1.797$ & $101.5 \%$ \\
\hline
\end{tabular}


Table 3. Absolute recovery of SU2162 in rat heart, liver, spleen, lung, kidney, brain $(n=3)$.

\begin{tabular}{l|llllll}
\hline $\begin{array}{l}\text { Concentration } \\
(\mu \mathrm{g} / \mathrm{ml})\end{array}$ & \multicolumn{2}{|c}{$\mathbf{0 . 4 0 0}$} & \multicolumn{2}{c}{$\mathbf{4 . 0 0}$} & \multicolumn{2}{c}{12.00} \\
\cline { 2 - 7 } & $\begin{array}{l}\text { Absolute } \\
\text { recovery } \\
(\%)\end{array}$ & $\begin{array}{l}\text { CV } \\
(\%)\end{array}$ & $\begin{array}{l}\text { Absolute } \\
\text { recovery } \\
(\%)\end{array}$ & $\begin{array}{l}\text { CV } \\
(\%)\end{array}$ & $\begin{array}{l}\text { Absolute } \\
\text { recovery } \\
(\%)\end{array}$ & $\begin{array}{l}\text { CV } \\
(\%)\end{array}$ \\
\hline Heart & 74.21 & 1.29 & 74.63 & 1.12 & 93.27 & 6.49 \\
Liver & 71.80 & 7.72 & 85.84 & 6.34 & 94.12 & 3.23 \\
Spleen & 70.95 & 2.15 & 71.74 & 4.33 & 80.88 & 6.50 \\
Lung & 71.55 & 11.96 & 66.02 & 7.21 & 93.77 & 5.82 \\
Kidney & 68.65 & 7.7 & 72.52 & 6.74 & 68.63 & 10.01 \\
Brain & 55.11 & 7.62 & 74.47 & 3.42 & 93.70 & 3.11 \\
\hline
\end{tabular}

with Kinetic Software version 5.0 (Therm, Innaphase Corp, Philadelphia, PA, USA). Plasma pharmacokinetics of SU2162 in the rat indicated a two-compartment model (weighting coefficient $\left.=1 / \mathrm{c}^{2}\right)$. Pharmacokinetic data of SU2162 are summarized in Table 4. The mean plasma concentration-time curve for SU2162 after administration (iv) is shown in Figure 2. The $T_{1 / 2 \mathrm{a}}$ and the $T_{1 / 2 \mathrm{~b}}$ for SU2162 were 0.1066 and $1.1407 \mathrm{~h}$, respectively, and the AUC was $5.2810(\mathrm{mg} / \mathrm{L}) * \mathrm{~h}$.

\section{Tissue distribution study}

Tissue distribution was measured in heart, liver, spleen, lung, kidney, brain samples at $0.03,0.1,0.42,0.83,1.33 \mathrm{~h}$ after SU2162 (5.5 mg/kg, iv). SU2162 concentrations in tissues at each time point are shown in Figure 3. Mean concentration versus time profiles of SU2162 in tissues are shown in Figure 4. Pharmacokinetics of SU2162 in tissues was calculated using Kinetic Software version 5.0 (Therm) and this is summarized in Table 5. At $0.03 \mathrm{~h}$ post-administration, SU2162 was greatest in

Table 4. Pharmacokinetics of SU2162 in rat.

\begin{tabular}{lll}
\hline Parameter & unit & Value \\
\hline $\mathrm{T}_{\max }$ & $\mathrm{h}$ & $0.0000 \pm 0.0000$ \\
$\mathrm{C}_{\max }$ & $\mathrm{mg} / \mathrm{L}$ & $9.3621 \pm 1.8474$ \\
$\mathrm{~A}$ & $\mathrm{mg} / \mathrm{L}$ & $6.7875 \pm 1.6979$ \\
$\mathrm{a}$ & $1 / \mathrm{h}$ & $6.5019 \pm 1.0036$ \\
$\mathrm{~B}$ & $\mathrm{mg} / \mathrm{L}$ & $2.5747 \pm 1.3351$ \\
$\beta$ & $1 / \mathrm{h}$ & $0.6076 \pm 0.3012$ \\
$\mathrm{~K}_{21}$ & $1 / \mathrm{h}$ & $2.2286 \pm 1.0362$ \\
$\mathrm{~K}_{12}$ & $1 / \mathrm{h}$ & $3.1082 \pm 1.4074$ \\
$\mathrm{~K}_{10}$ & $1 / \mathrm{h}$ & $1.7728 \pm 1.0881$ \\
$\mathrm{~T}_{1 / 2 a}$ & $\mathrm{~h}$ & $0.1066 \pm 0.0593$ \\
$\mathrm{~T}_{1 / 2 \beta}$ & $\mathrm{h}$ & $1.1407 \pm 0.5791$ \\
$\mathrm{~T}_{1 / 2 \mathrm{kel}}$ & $\mathrm{h}$ & $0.3910 \pm 0.0012$ \\
$\mathrm{Vc}$ & $\mathrm{L} / \mathrm{Kg}$ & $0.5874 \pm 0.3262$ \\
$\mathrm{Vss}$ & $\mathrm{L} / \mathrm{Kg}$ & $1.4066 \pm 0.9004$ \\
$\mathrm{AUC}$ & $(\mathrm{mg} / \mathrm{L})^{\star} \mathrm{h}$ & $5.2810 \pm 0.9672$ \\
$\mathrm{CL}$ & $\mathrm{L} / \mathrm{h}$ & $0.3115 \pm 0.1771$ \\
\hline
\end{tabular}

Data are expressed as averages $( \pm \mathrm{SD})$

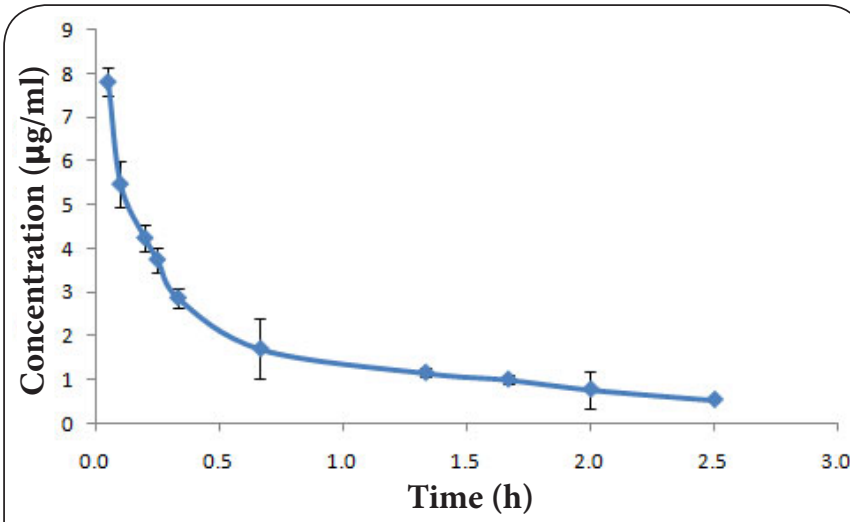

Figure 2. A plot of plasma concentrations of SU2162 in rat against time.

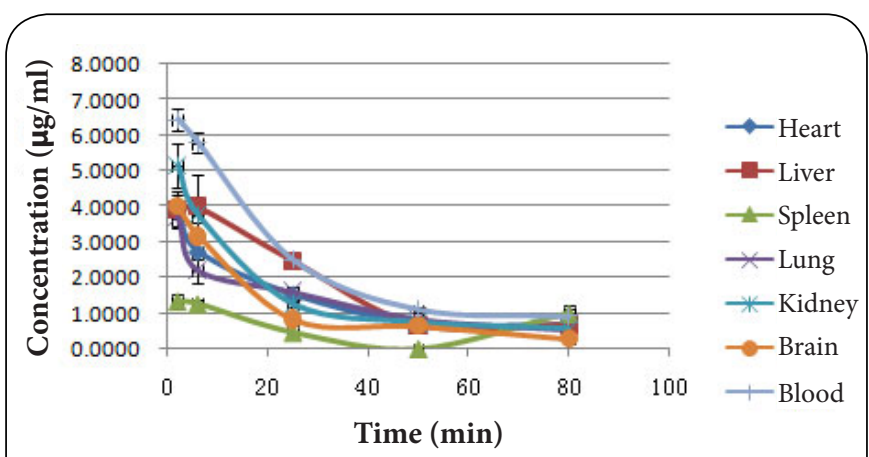

Figure 3. Concentrations of SU2162 in different tissues and different time after intravenous administration to rat.

Table 5. Pharmacokinetics of SU2162 in different tissues.

\begin{tabular}{llll}
\hline Tissue & $\mathbf{C}_{\max }(\mathbf{m g} / \mathbf{l})$ & $\mathrm{T}_{\max }(\mathbf{h})$ & $\left.\mathbf{A U C}(\mathbf{m g} / \mathbf{l})^{\star} \mathbf{h}\right)$ \\
\hline Heart & $3.9297 \pm 0.6361$ & $0.0300 \pm 0.0012$ & $2.2304 \pm 0.6291$ \\
Liver & $3.9943 \pm 1.3012$ & $0.1000 \pm 0.0012$ & $2.6847 \pm 0.3502$ \\
Spleen & $1.3454 \pm 0.3011$ & $0.0300 \pm 0.0012$ & $6.7685 \pm 0.6575$ \\
Lung & $3.6828 \pm 0.9075$ & $0.0300 \pm 0.0012$ & $2.1688 \pm 1.0072$ \\
Kidney & $5.1602 \pm 1.9054$ & $0.0300 \pm 0.0012$ & $2.5829 \pm 0.5701$ \\
Brain & $4.0297 \pm 1.1802$ & $0.0300 \pm 0.0012$ & $1.6549 \pm 0.4326$ \\
\hline
\end{tabular}

all tissues except for the liver, which had a peak concentration at $0.1 \mathrm{~h}$.

\section{Discussion}

We investigated the pharmacokinetics and tissue distribution of SU2162 in the rat after administration (iv) using a reliable HPLC method. SU2162 depicted a two-compartment model in the rat (weighting coefficient $=1 / \mathrm{c}^{2}$ ). Table 4 shows these data. $\mathrm{K}_{12}$ and $\mathrm{K}_{21}$ data suggest the SU2162 in the rat is distributed quickly after administration, and that a distribution equilibrium between the peripheral and central compartment is attained in a short time. 


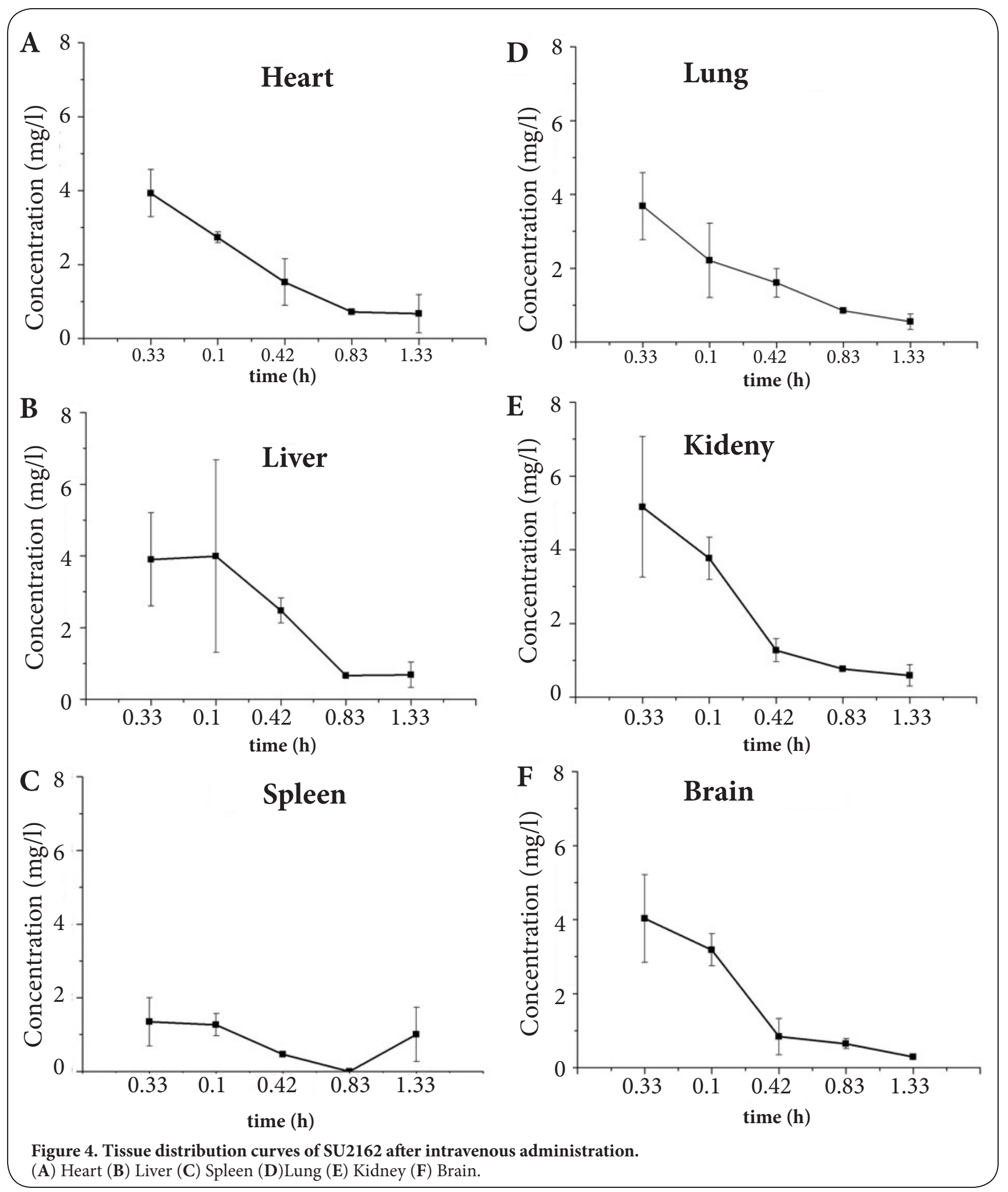

SU2162 was distributed widely in rat tissue with the highest AUC in the spleen, followed by the liver and kidney. The smallest disposition rate constant (LZ) of SU2162 in liver was the maximum. The $L Z$ value in the spleen was the minimum, followed by the kidney. The liver $\mathrm{T}_{1 / 2}$ was the shortest, and the spleen $T_{1 / 2}$ was the longest. The mean residence time (MRT) 
in the liver was the greatest and the smallest in the kidney. SU2162 accumulated more in the spleen and the elimination rate there was the slowest. Hepatic SU2162 accumulation was significant, too-and clearance of SU2162 was fast, suggesting that the liver may be a therapeutic target for cancer treatment.

In Asia, especially in China's coastal areas, liver cancer is a serious concern. From 1998 to 2007, in China the incidence of liver cancer accounted for $25.84 \%$ of cancer cases. And the incidence of liver cancer had increased between 2008 and 2015 [8].

In fact, drugs which can be used to treat liver cancer are very few. This lack of an effective liver targeting drug may seem being a problem. The design and developing the targeted therapy medicine for liver cancer has the significant meaning. Especially for disease survival rate and cure rate.

Parent- compound of the SU2162 is an original extract from an insect Mylabris cichorii L.de. Our ancestor had used this kind of insect as traditional Chinese medicine for the liver disease and already had outstanding result. Cantharidin is the active ingredient in this Chinese medicine. Yet although the Cantharidin has the strong power to cure the cancer cell, the side effect is still a major concern. In clinical, the urinary toxicity had been observed [9]. Therefore there come to the norcantharidin, which is the derivative from the Cantharidin and with much less toxicity and has the incredible effectiveness on the liver cancer [10]. The Patent compound SU2162 is the derivative from the norcantharidin and we optimized the chemical structure to lower the urinary toxicity. Here our study was focus on the Pharmacokinetics and tissue distribution. It's essential to get those basic pharmacokinetics data for a whole new compound. As we know, successful development of a new drug ultimately depends on the absorption characteristics, and overall capacity of the drug to modulate the magnitude and duration of an anticipated pharmacological response. A series of in vivo performances evaluations and pharmacokinetic data from animal studies can provide useful preliminary information about drug absorption rates. Animal data can also offer early insights into potential mechanisms of drug distribution, metabolism, and elimination. The data shows the SU2162 has the high hepatic accumulation which indicated that maybe SU2162 has liver affinity (liver was the second widely distributed organ and the residence time in liver was the greatest). And the SU2162 might have the potential as the fine drug for the target treatment of liver cancer.

Renal accumulation of SU2162 approximated that of the liver, and the renal clearance was slow. We also noted that rats had occasional hematuria, suggesting renal or urinary adverse effects that may require monitoring.

\section{Conclusion}

As the development phase of an investigational drug product progresses, in vivo animal studies are typically conducted before any human studies are initially performed. Animal models can effectively be used to obtain early pharmacokinetic knowledge of a new drug's absorption characteristics. Fundamental animal data can also be used to document preliminary mechanisms of a novel drug absorption, distribution, metabolism, and elimination. Consequently, animal data from in vivo pharmacokinetic evaluation are often used to support selection of a novel drug or an optimal formulation, and to guide the overall design of the final product's dosage form. In the study, our pharmacokinetic data from animal in vivo show that SU2162 is eliminated quickly in the rat and extensively distributes to tissues, and it has characteristic liver targeting, specifically, and warrants further development as anticancer candidate.

\section{Competing interests}

The authors declare that they have no competing interests.

\section{Authors' contributions}

\begin{tabular}{|l|c|c|c|c|c|c|c|c|c|c|c|}
\hline Authors' contributions & ZT & HY & RY & RL & XL & QY & WG & XZ & YH & CT & WC \\
\hline $\begin{array}{l}\text { Research concept and } \\
\text { design }\end{array}$ & $\checkmark$ & $\checkmark$ & $\checkmark$ & -- & -- & $\checkmark$ & $\checkmark$ & -- & -- & -- & -- \\
\hline $\begin{array}{l}\text { Collection and/or } \\
\text { assembly of data }\end{array}$ & $\checkmark$ & $\checkmark$ & $\checkmark$ & $\checkmark$ & $\checkmark$ & $\checkmark$ & $\checkmark$ & $\checkmark$ & $\checkmark$ & $\checkmark$ & $\checkmark$ \\
\hline $\begin{array}{l}\text { Data analysis and } \\
\text { interpretation }\end{array}$ & $\checkmark$ & $\checkmark$ & $\checkmark$ & $\checkmark$ & $\checkmark$ & $\checkmark$ & $\checkmark$ & $\checkmark$ & $\checkmark$ & $\checkmark$ & $\checkmark$ \\
\hline Writing the article & $\checkmark$ & $\checkmark$ & $\checkmark$ & -- & -- & $\checkmark$ & $\checkmark$ & -- & -- & -- & -- \\
\hline $\begin{array}{l}\text { Critical revision of the } \\
\text { article }\end{array}$ & $\checkmark$ & $\checkmark$ & $\checkmark$ & -- & -- & -- & -- & -- & -- & -- & -- \\
\hline Final approval of article & $\checkmark$ & $\checkmark$ & $\checkmark$ & -- & -- & -- & -- & -- & -- & -- & -- \\
\hline Statistical analysis & $\checkmark$ & $\checkmark$ & $\checkmark$ & $\checkmark$ & $\checkmark$ & $\checkmark$ & $\checkmark$ & $\checkmark$ & $\checkmark$ & $\checkmark$ & $\checkmark$ \\
\hline
\end{tabular}

\section{Acknowledgement}

We gratefully acknowledge financial support from the Science and Technology Project of the Government of Guangdong Province, China (grant No. 2009B080701025).

Publication history

Editor: Abdul Ahad, King Saud University, Saudi Arabia. EIC: James Radosevich, University of Illinois, USA. Received: 04-June-2013 Final Revised: 01-Apr-2014 Accepted: 04-Apr-2014 Published: 18-Apr-2014

\section{References}

1. O'Callaghan T. Introduction: The prevention agenda. Nature. 2011; 471:S2-4. | $\underline{\text { Article | PubMed }}$

2. Tan Z. China, Patent No.200710029736.1. 2008.

3. Tan Z, Luo L, Zhu E, Yan R and Lin Z. (3aRS,4SR,7RS,7aSR)-2(Tricyclo-[3.3.1.1]decan-1-yl)-4,5,6,7-tetra-hydro-4,7-epoxy-isoindoline1,3-dione. Acta Crystallogr Sect E Struct Rep Online. 2010; 66:01374. | Article I PubMed

4. Z.Y. Tan, L. Luo, E.J. Zhu, Lin Z.H. Lin, R.S. Yan, H. Zhang and K. Liang. Preparation and $X$-ray diffraction analysis of a new crystal form of (3aRS,4RS,7RS,7aSR)-2-(tricyclo[3.3.1.1,7]decan-1-yl)-4,5,6,7tetrahydro-4,7-epoxyisoin-doline- 1,3-dione- a novel anticancer compound. J. Journal of Guangdong Pharmaceutical College. 2010; 26: 441-444.

5. ZaiYou Tan, RuiSi Yan, JiaHui Lu, Qing Ye, WanShen Guan, XiaoLu Zhang and Hui Yang. Determination of (3aRS,4SR,7RS,7aSR)2-(Tricyclo-[3.3.1.1 1,7] decan-1- yl)-4,5,6,7-tetrahydro-4,7epoxyisoindoline-1,3-dione (SU2162) in rat plasma by highperformance liquid chromatography with UV detection. The Analytical 
Tan et al. Journal of Pharmaceutical Technology \& Drug Research 2014,

http://www.hoajonline.com/journals/pdf/2050-120X-3-1.pdf

Chemistry. 2012; 11:347-352. | Article

6. Sunil S Jambhekar and Philip J Breen. Basic Pharmacokinetics [M].

Pharmaceutical Press. [London.Chicago]. 2009; 1-1. | Article

7. David G.Watson. Pharmaceutical Analysis,A Textbook for Pharmacy Students and Pharmaceutical Chemists. Churchill Livingstone (London). 2009; 1-11:238-274. | Article

8. Zhang SW, Zheng RS, Li N, Zeng HM, Dai Z, Zou XN and Chen WQ. [Analysis and prediction of liver cancer incidence in China]. Zhonghua Yu Fang Yi Xue Za Zhi. 2012; 46:587-92. | Article | PubMed

9. Zhang JP, Qian DH and Qi LH. Effects of cantharidin on interleukin-2 and interleukin-1 production in mice in vivo. Zhongguo Yao Li Xue Bao. 1992; 13:263-4. | PubMed

10. LI Bo and LING Changquan. Advances in basic and clinical studies of norcantharidin [J]. Chinese Traditional and Herbal Drug. 2002; 33:184185.

\section{Citation:}

Tan Z, Yang H, Yan R, Liu R, Li X, Ye Q, Guan W, Zhang $\mathrm{X}$, Huang $\mathrm{Y}$, Tong $\mathrm{C}$ and Chen W. Pharmacokinetics and tissue distribution of SU2162, a novel anticancer drug, after intravenous administration in rats. $J$

Pharm Technol Drug Res. 2014; 3:1.

http://dx.doi.org/10.7243/2050-120X-3-1 